\title{
The Role of Internal Control in Reducing Administrative and Financial Corruption Applied Research at the Technical Institute / Nasiriya
}

\author{
Hamida Athab Khudair ${ }^{1}$, Ali Khalaf Gatea ${ }^{2}$ \\ \{Hameedah.athab@stu.edu.iq ${ }^{1}$, ali.khalaf83@stu.edu.iq $\left.{ }^{2}\right\}$
}

Southern Technical University - Technical Institute / Nasiriya ${ }^{1,2}$

\begin{abstract}
The research aims to identify the role of internal control in reducing administrative and financial corruption, the necessity of diagnosing its causes, how to eliminate or reduce the phenomenon of corruption, and how to optimally use the institution's resources, as a questionnaire was designed to determine the nature of the relationship between internal control and administrative and financial corruption. Supporting the research hypotheses and reaching the most important conclusions that support the objectives of the research, which states that corruption negatively affects the stability of the social and political system and limits its ability to respect citizens' rights, equality, and equal opportunities. The research also recommended the necessity of paying attention to social upbringing and instilling the prevailing cultural values that establish morals and positive behaviour in society and spreading the advanced civilizational awareness that rejects corruption of all kinds.
\end{abstract}

Keywords: Internal Control, Individuals, Organizational Structure, Legal Reform, Administrative Procedures. 


\section{Introduction}

The issue of administrative and financial corruption is a complex topic. Researchers differ on how to diagnose, analyse and suggest appropriate solutions to combat it. Corruption has become a global phenomenon at the level of states and individuals, in addition to its negative effects in reducing the effectiveness of political decisions, weakening the moral and ethical authority of society, and reducing the phenomenon of corruption. The administrative system will be a goal and a means to reach other goals related to the judiciary or mitigating the severity of this phenomenon because of its societal impact, and if governments are interested in fighting administrative corruption and rationalizing money management, and developing means of control and accountability, the success of this depends on the efficiency of the administrative system that is concerned with setting Objectives, control plans and evaluation, which help to achieve this, so internal control is the starting point at which the auditor begins his work. And financial - and a study of the internal control system and its role in reducing administrative and financial corruption.

\section{Previous Studies}

A Study (Andersson \& Vilo, 2016) "How do Internal Auditors Become Comfortable in Their Role within Risk Management": The study aims at the extent to which the environment surrounding the work of the internal auditor affects the peace of work within the organization, and the provision of assurance, guarantee, and management consultancy services to the higher authorities within the organization, and what are the concerns that they may face, when providing a neutral technical opinion, which can add value to the organization, As a result, adequate safeguards must be provided to protect them from the consequences of expressing an opinion inside and outside the work environment, to make them feel comfortable when performing their role.

A study (Claros, 2013) "Removing Impediments to Sustainable Economic Development the Case of Corruption (removing obstacles to economic development, corruption as a model": The study aims to search for the causes and results of corruption in the process of economic development, by reviewing some of the factors that turned corruption into an influential factor in economic development, by studying the data of a selected group of countries working to combat corruption, over the past two decades and in cooperation with the World Bank. Corruption affects public finances, the characteristics, and the performance of the private sector, and it causes distortions in resource allocation and supply chains.

A study (Samieh \& Bastanioour, 2016)" Against Administrative Corruption within Governmental Organizations from Motto to Practice": The study aims to provide solutions to combat administrative corruption by classifying workers, based on explaining the relationship between their awareness and their commitment to the complex situations they face during the performance of their job duties, and relied on a survey of the views of several workers, about patriotism and organizational culture, and the results of the research concluded that the perpetrators of The crime of corruption can be divided into three categories, a category that 
includes employees who realize that corruption is a positive phenomenon and do not see it as an ominous and ominous phenomenon, and the category of employees who realize and feel that corruption is a negative phenomenon, and the third category is employees who realize that corruption is a negative phenomenon, but their feeling is uncertain. and commit it.

\section{Literature Review}

\subsection{The Concept of Internal Control}

There was no firm agreement on the nature of internal control, as a commercial concept for the provisions of control over private sector activities, or a financial accounting sense, aimed at preserving public property in the public sector[9], but the American Institute of Certified Public Accountants (AICPA) and the Securities and Exchange Commission (SEC) set a starting point in 1934, as an internal control was defined as an independent activity that divides the work of internal controls for organizations and provides advice to achieve goals at the lowest possible cost, and at the same time contribute to improving its operations and uses its controls to verify the risks inherent in the organization. [12], as defined as a process implemented by the board of directors and its delegated personnel to provide reasonable assurance to achieve the highest efficiency and effectiveness of operations within the organization, reliability of financial reporting, and compliance with applicable laws and regulations, [13], while it defines it [6]. It is an evaluation activity that is established within the organization, as a service whose functions include examining, evaluating, and monitoring the adequacy and effectiveness of accounting systems. While we see that internal control is the commitment to the standards, measures, and procedures set by the administration to preserve its assets, and to ensure the accuracy of its records, in addition to achieving the organization's goals related to the reliability of financial reporting.

\subsubsection{Internal Control Objectives}

The main objectives of the internal control system in auditing practices can be summarized as follows: [9]
a. Managing its business in an orderly and effective manner, including adherence to internal policies.
b. Protecting the organization's assets
c. Prevention and detection of fraud and error
d. Accuracy and completeness of accounting records.
e. Preparing financial information promptly.

\subsubsection{Dimensions of Internal Control}

There is a set of dimensions that control the effectiveness of the internal control systems within the organization, including the following:

a) Organizational structure: Its presence is the basis of the control process in the organization, to achieve functional independence between the different departments, as well as the separation of functional responsibilities to protect against intentional errors, which must have sufficient flexibility, to allow for adjustments required by 
changes in policies and objectives of the organization, and to meet the objectives of internal control [3].

b) Individuals: Individuals are one of the most important factors affecting the effectiveness of internal control systems, whether workers within the organization or individuals with interests and who are involved in acts of corruption, which can be part of the solution in eliminating administrative and financial corruption by evaluating the costs and benefits of their work and making nutrition Reversible to internal control procedures and thus corruption can be effectively controlled [11].

\subsubsection{Components of the Internal Control System}

The internal control system helps the organization achieve its goals by providing a systematic and disciplined approach to assessing risk management and improving governance processes [4]. The internal control system in small organizations may be less formal and unstructured than in large organizations. The internal control system is as follows [1]:

a. Control environment: The internal control environment is the basic component for all other components because it requires management and employees to demonstrate commitment, integrity, and ethical values.

b. Risk assessment: is the practice of identifying, analysing, and managing risks that could prevent the organization from achieving its goals.

c. Control activities: There is a set of different control activities that can be applied to enhance the application of strong internal control systems, including preventive activities such as the separation of duties, and investigative activities such as bank reconciliations.

d. Information and Communication: Relevant and qualitative information is identified, captured, and communicated promptly, in a way that allows employees to perform their responsibilities, and the organization's management must ensure the immediate link between information related to internal control, which is necessary to improve supervisory performance.

\subsection{Administrative and Financial Corruption}

There is a consensus that corruption is harmful to society, as it distorts and affects the distribution of income and hinders investment, as well as causes inefficiency, waste of resources, and damage to society. and its organizations and violating regulatory instructions [5]. While corruption was defined in the administrative aspect as the result of illegal acts, deviant bureaucratic behaviour, and the exploitation of workers for their positions and tasks, that is, the exploitation or misuse of the public service for personal gain [2]. From the foregoing, we see that financial corruption is an illegal behaviour related to wasting public money and exploiting it to achieve private interests. As for administrative corruption, it is a behaviour related to administrative and functional deviations in violation of regulations, laws, and controls, to achieve personal interest at the expense of the public interest. Thus, administrative, and financial corruption is a distant behaviour for legal legislation aims to achieve private interests. 


\subsubsection{The Basics of Reducing Administrative Corruption}

There are important basics that help reduce administrative and financial corruption, the most important of which are the following:

a) Administrative procedures: The administrative apparatus is the first affected by corruption, and some measures can reduce the demand for services contaminated with corruption, which make individuals or the private sector resort to illegal activities, and this is done by cancelling or reducing administrative procedures, to facilitate Work in various social and economic fields, and the demand for corrupt activities can also be reduced by enhancing public awareness, as the lack of knowledge and learning is one of the main factors that help in the spread of corruption, so promoting awareness of its harmful effects and the need to combat corruption is among the things It is the optimum achievement of the set goals and is considered one of the contents of internal control to preserve assets from embezzlement and misuse [11].

b) Legal reforms: Legal reform is a process represented in studying existing laws, calling for changes in legal systems and instructions for their implementation, to enhance societal justice or efficiency and integrity in providing services. This term is closely related to law reform bodies or law committees. And work on developing laws to keep pace with the challenges facing the work of organizations, whether in the public or private sectors [14].

\subsubsection{Causes of Corruption (Practices)}

The causes of corruption in practice must be identified, and special attention will be paid to economic, political, and agency interpretations [5].

a. Economic interpretation: The specific economic variables that have an impact on corruption are very diverse, and are often discussed in the so-called corrupt dependency theories in third world countries, and are caused by the weak level of control as a result of capitalist exploitation, in addition to political tyranny and weak economic development, and the existence of corruption Linked to economic underdevelopment and economic crises that reflect common causes of increased corruption, and thus the debate remains about how economic growth can limit administrative and financial corruption.

b. Political interpretation: The level of corruption is also affected by the political system that deals with it, and among these different political systems there is a general assumption that the level of democracy, leads to reducing or limiting the level of corruption, and this is what Friedrich says in that the degree of corruption varies inversely With the degree of compatibility of the authority, the greater the legitimacy of the authority in society, the less corruption is, while the practices of administrative and financial corruption spread to a large extent in the least democratic countries.

\section{Research Methodology \\ 4.1 Research Problem}


Phenomena arose related to the improper behaviour of the individual, which is represented by the lack of integrity of individuals (behaviourally, functionally, materially), which is one of the phenomena with a negative impact on the economy, and that weak control makes it an obstacle in the way of progressing development and achieving the set goals, and the research problem lies in the following questions:

a) Is administrative and financial corruption practiced in a systematic and coordinated manner in public jobs?

b) Have the causes of administrative and financial corruption been diagnosed?

c) Can successful solutions be developed to address or reduce administrative and financial corruption?

\subsection{Research Importance}

Corruption in government units leads to waste of resources, slows down the process of economic growth and quality of life, and reduces the value of credibility for state agencies and their sound concepts that were developed for them. Finding means to combat the scourge of financial and administrative corruption, whether at the state level or the level of the organization and the individual.

\subsection{Research Object}

The research aims to answer the questions of the problem, which can be summarized as follows:

a) Identify the encouraging factors for the spread of the phenomenon of administrative and financial corruption.

b) Identify the role of internal control in diagnosing corruption cases.

c) Coming up with results that help develop successful solutions and eradicate the phenomenon of corruption.

\subsection{Research Hypothesis}

To reach sound answers and scientific solutions to the problems raised in this research, and to achieve the desired goal, the research seeks to test the following hypotheses:

H1: There is a significant correlation relationship between the dimensions of the independent variable internal control and the dimensions of the dependent variable, administrative and financial corruption.

$\mathrm{H} 2$ : There is a significant effect relationship between the dimensions of the independent variable internal control and the dimensions of the dependent variable, administrative and financial corruption.

\subsection{Limits and Sample Research}

a) Relevant supervisory and administrative units at the Technical Institute / Nasiriya.

b) The research sample is represented by (heads of departments, units and divisions, teachers, technicians, and administrators).

\subsection{Research Model}

Based on the intellectual framework of the literature and considering the research problem and its objectives, it required the construction of a proposed comprehensive model, to diagnose the 
relationship between internal control processes, administrative and financial corruption, and the trends of influencing them. The research model included two types of variables, which are as follows:

a) Independent variables: represented by the internal control variables, including (organizational structure, individuals)

b) The approved variables: represented by the administrative and financial corruption variables. Two of these variables have been selected, namely (legal reform, administrative procedures).

\section{Data Collection and Analysis}

The data processing was relied on the statistical program (spss) to obtain the following:

a. Frequency and percentages and their purpose are to describe the research sample.

b. The arithmetic mean is used to analyse data related to the role of internal control in reducing administrative and financial corruption.

c. Standard deviation to measure the degree of dispersion of the response value of service providers from the arithmetic mean.

d. Correlation coefficient to measure the strength of the relationship between the study variables.

\subsection{Describe The Characteristics of The Study Sample}

The questionnaire was conducted at the Technical Institute in Dhi Qar Governorate, and the Institute consists of eleven scientific departments and several administrative units, including scientific, financial, self, and other units, and it employs about 400 employees with various certificates. Table (1) indicates the number of forms distributed and retrieved by respondents. The number of the distributed forms was (40), and the number of the retrieved form was (40), which means that the retrieval rate was $(100 \%)$, and the study sample included some employees of the Technical Institute in Nasiriya. the results were subjected to a statistical analysis based on the outputs of the (SPSS) program and the impact and correlation it contains significant significance at the degree of freedom (0.05), which was as follows :

Table 1. Case Processing Summary.

\begin{tabular}{cccc}
\hline Cases & N & $\%$ \\
& Valid & 40 & 100.0 \\
& Excluded $^{\mathrm{a}}$ & 0 & .0 \\
Total $^{2}$ & 40 & 100.0 \\
\hline Listwise deletion based on all variables in the procedure. \\
Table (1) shows the SPSS program entries, which were $100 \%$ correct. \\
\hline
\end{tabular}

Table 2. Study sample by gender.

\begin{tabular}{cccc}
\hline Target & sample variables & Frequency & percentage \\
& Male & $\mathbf{2 0}$ & $50 \%$ \\
gender & Female & 20 & $50 \%$ \\
total & & 40 & $100 \%$ \\
\hline
\end{tabular}


Prepared by researchers based on the outputs of the spss program

The statistical results presented in Table (2) showed that the percentage of males in the surveyed sample is equal to the percentage of females. As for the age group, the statistical results are shown in Table (3) showed that the percentage of $(52.5 \%)$ of the sample members was between (31-40) and represented the highest percentage, then came the category (41-50), where it reached The percentage of this category (30\%), and the category (51-60) reached $(12.5 \%)$, then the category (21-30) at the rate of (5\%), and the category (25 years and less) reached (3.3\%), and the lowest percentage was As for the category (50 years and over), its percentage was zero.

Table 3. The research sample by age group.

\begin{tabular}{|c|c|c|c|}
\hline Variables & target sample & repetitions & percentage \\
\hline \multirow{5}{*}{ Age group } & -20 & 0 & $\% 0$ \\
\hline & $30-21$ & 2 & $\% 5$ \\
\hline & $40-31$ & 21 & $\% 52.5$ \\
\hline & $50-41$ & 12 & $\% 30$ \\
\hline & $60-51$ & 5 & $\% 12.5$ \\
\hline Total & & 40 & $100 \%$ \\
\hline
\end{tabular}

Table 4. Description of the research sample by academic qualification.

\begin{tabular}{cccc}
\hline Variables & target sample & Frequency & percentage \\
& Secondary & $\mathbf{1}$ & $2.5 \%$ \\
& Technical Diploma & 16 & $40 \%$ \\
Educational Qualification & Bachelor & 13 & $32.5 \%$ \\
& Higher Diploma & 2 & $5 \%$ \\
& M.A. & $\mathbf{6}$ & $\mathbf{1 5 \%}$ \\
Total & PhD & 2 & $5 \%$ \\
Prepared by & & 40 & $100 \%$
\end{tabular}

Prepared by researchers based on the outputs of the spss program

The statistical results contained in Table (5) showed that the percentage of department heads in the respondents was $(15 \%)$, while the percentage of teachers was (17.5), and the percentage of employees in the sample amounted to (67.5)

Table 5. Description of the research sample by job position.

\begin{tabular}{cccc}
\hline Variables & target sample & Frequency & percentage \\
& Heads of Departments & 6 & $\% 15$ \\
job position & Administrators & 7 & $\% 17.5$ \\
& employee & 27 & $\% 67.5$ \\
Total & & 40 & $100 \%$ \\
\hline Prepared by researchers based on the outputs of the spss program
\end{tabular}

Prepared by researchers based on the outputs of the spss program 
As for the number of courses that the research sample benefited from in developing supervisory skills, the statistical results contained in Table (6) showed that $(52.5 \%)$ of the sample individuals participating in the courses ranged between (4-6) and represented the highest percentage, then Then comes the courses that range between (1-3), where the percentage of these courses reached (20\%), the courses (10 and more) reached (15\%), and then courses (7-9) with a rate of (12.5\%).

Table 6. Study sample by the number of courses.

\begin{tabular}{cccc}
\hline variables & target sample & Frequency & percentage \\
& - & 0 & $\% 0$ \\
Subscribed courses & $3-1$ & 8 & $\% 20$ \\
& $6-4$ & 21 & $\% 52.5$ \\
& $9-7$ & 5 & $\% 12.5$ \\
Total & $10-$ & 6 & $\% 15$ \\
& \multicolumn{4}{c}{40} & $\% 100$ \\
\hline Prepared by researchers based on the outputs of the spss program
\end{tabular}

\subsection{Presenting The Results Related To The Role of Internal Control and The Basics of Reducing Administrative and Financial Corruption}

Based on the answers of the study sample members to the questionnaire items to identify the differences in their opinions and provide a comprehensive perception of their views on the nature of these variables, the frequency distribution tables, percentages, and arithmetic means were used to estimate the levels and standard deviations, and to estimate the extent of dispersion in the answers around the arithmetic means (as It is shown in Table (3-1), and light of the statistical treatment presented by the mentioned table, it is clear that the opinions and attitudes of the study sample members tend towards the positive direction, based on the Likert quintuple scale, as it reflects arithmetic means higher than the hypothetical arithmetic mean of the scale (3), as next one:

a. Organizational Structure (x1): The percentage of those whose answers were in agreement on this stage was $(8.53 \%)$ of the sample, with arithmetic mean (52.3), and a standard deviation (542.0), and in contrast, the percentage of The lack of agreement on this stage for the answers of the study sample members is (10\%), and the percentage sometimes reached $(2.36 \%)$, which indicates that more than half of the sample support the existence of an effective and clearly defined organizational structure

b. Individuals and the organization's work (x2): The percentage of those whose answers were in agreement in the stage reached $(3.38 \%)$ of the sample, and in contrast, the percentage of disagreement among the respondents' answers is $(4.28 \%)$, and sometimes (3 33\%), and the arithmetic mean amounted to (2.3), with a standard deviation of (833.0), which means that less than half of the sample members indicate the presence of influential individuals in the effectiveness of internal control systems.

c. The basics of reducing administrative and financial corruption (legal reform y1), and the percentage of those whose answers, when agreeing on the formula for reducing corruption (legal reform), were $(8.48 \%$ ) of the sample, with an arithmetic mean of (31.3), and a standard deviation of (89.0), and in contrast, the percentage of 
disagreement among the answers of the study sample members reached $(2.26 \%)$ and sometimes $(25 \%)$. The above percentages indicate that less than half of the sample confirms the availability of the legal reform factor to increase the Effectiveness of reducing administrative and financial corruption

d. The basics of reducing administrative and financial corruption (administrative procedures y2), and the percentage of those whose answers were in the case of agreement on the basics of reducing corruption (administrative procedures) reached $(50 \%)$ of the sample, with arithmetic mean (5.3), and a standard deviation (98.0), in contrast, the percentage of disagreement and sometimes the answers of the sample members represent only $(7.18 \%)$ and $(3.31 \%)$, respectively, and these percentages indicate that half of the study sample members confirm here the existence of administrative procedures that help organization to make rational decisions that are in the public interest.

The opinions of the study sample members and their attitudes towards the role of internal control and the basics of reducing administrative and financial corruption in the institute, the study sample

Table 7. Summary severely.

\begin{tabular}{|c|c|c|c|c|c|c|c|c|c|c|c|c|}
\hline \multirow{2}{*}{ Dimensions } & \multicolumn{2}{|c|}{$\begin{array}{l}\text { I do not } \\
\text { agree }\end{array}$} & \multicolumn{2}{|c|}{ disagree } & \multicolumn{2}{|c|}{$\begin{array}{l}\text { Sometime } \\
\text { s I agree }\end{array}$} & \multicolumn{2}{|c|}{ Agreed } & \multicolumn{2}{|c|}{ Strongly } & \multirow{2}{*}{ mean } & \multirow{2}{*}{ Std. d } \\
\hline & FR. & $\begin{array}{c}\mathrm{PR} \\
.\end{array}$ & $\begin{array}{l}\mathrm{F} \\
\mathrm{R} .\end{array}$ & PR. & $\begin{array}{l}\mathrm{F} \\
\mathrm{R} .\end{array}$ & PR. & $\begin{array}{l}\mathrm{F} \\
\mathrm{R} .\end{array}$ & PR. & $\begin{array}{l}\mathrm{F} \\
\mathrm{R} .\end{array}$ & PR. & & \\
\hline $\mathrm{X} 1$ & 2 & 8,0 & 22 & 2,9 & 87 & 2,36 & $\begin{array}{c}10 \\
6\end{array}$ & $\begin{array}{c}2,4 \\
4\end{array}$ & 23 & 6,9 & 52,3 & 542,0 \\
\hline $\mathrm{X} 2$ & 5 & 5,4 & 29 & $\begin{array}{c}2,2 \\
4\end{array}$ & 40 & 3,33 & 31 & $\begin{array}{c}8,2 \\
5\end{array}$ & 15 & $\begin{array}{c}5,1 \\
2\end{array}$ & 2,3 & 833,0 \\
\hline Y1 & 9 & 6,5 & 33 & $\begin{array}{c}6,2 \\
0\end{array}$ & 40 & 25 & 55 & $\begin{array}{c}4,3 \\
4\end{array}$ & 23 & $\begin{array}{c}4,1 \\
4\end{array}$ & 31,3 & 89,0 \\
\hline $\mathrm{Y} 2$ & 10 & 2,6 & 20 & $\begin{array}{c}5,1 \\
2 \\
\end{array}$ & 50 & 3,31 & 46 & $\begin{array}{c}7,2 \\
8\end{array}$ & 34 & $\begin{array}{c}3,2 \\
1 \\
\end{array}$ & 5,3 & 98,0 \\
\hline Prepared by re & & ase & $n$ & outp & & 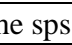 & & & & & & $\mathrm{n}=40$ \\
\hline
\end{tabular}

\subsection{Correlation Analysis of The Role of Internal Control in Reducing Administrative and Financial Corruption}

Here it is necessary to verify the hypothesis whose content states that there is a significant correlation between internal control and the basics of reducing administrative and financial corruption. Based on this, the Pearson correlation coefficient is used to find the strength of the relationship between the study variables. The results reveal the existence of a positive significant relationship between internal control (x) in terms of all its dimensions and its impact on reducing corruption ( $y$ ) and in terms of the basics of reducing administrative and financial corruption completely, where the value of the correlation between the two variables reached $(691,0)$, which is a positive value that indicates the strength of the relationship between the two variables. The correlation coefficient between internal control and the basics of reducing administrative and financial corruption was as follows: 
a. Organizational Structure (x1): Legal reform $(0,574)$ and administrative procedures (0.636) which is a positive moral value indicating that the technical institute (the study sample) can highlight the general framework of the organizational structure

b. Individuals and business of the organization (x2): Legal reform (0.411), and administrative procedures (0.500), which is a positive value indicating that the technical institute (the study sample) possesses individuals who abide by administrative and legal procedures, regulations, and instructions, From the foregoing, the study concludes that the test results for the relationship between internal control in terms of all its dimensions, and the reduction of corruption in terms of the basics of building it in a complete and moral sense, and between the role of internal control, and the basics of reducing administrative and financial corruption are moral, and this proves the validity of the hypothesis whose content states that there is a relationship Morale between internal control and the basics of reducing corruption.

Table 8. Values of Pearson correlation coefficient between research variables.

\begin{tabular}{r|c|c}
\hline & \multicolumn{2}{|c}{$\mathrm{X}$} \\
$\mathrm{Y}$ & \multicolumn{2}{|c}{$0.691 *$} \\
& $\mathrm{X} 1$ & $\mathrm{X} 2$ \\
$\mathrm{Y} 1$ & $0.574 * *$ & $0.411^{* *}$ \\
$\mathrm{Y} 2$ & $0.636 * *$ & $0.500 * *$ \\
\hline
\end{tabular}

Table 9. Reliability Statistics.

\begin{tabular}{ccc}
\hline $\mathrm{N}$ of Items & Cronbach's Alpha Based on Standardized Items & Cronbach's Alpha \\
\hline 39 & .829 & .829 \\
\hline & $\begin{array}{l}\text { The reliability coefficient of the questionnaire items is .829, } \\
\text { which is an excellent percentage for measuring the validity } \\
\text { of the questions that were included within the questionnaire. }\end{array}$ \\
\hline
\end{tabular}

\section{Conclusions and Recommendations}

In light of the results presented and analysed in the theoretical and applied frameworks of the studies, the following conclusions were reached:

a. Corruption negatively affects the stability and reputation of the political system and limits its ability to respect citizens' rights, equality, and equal opportunities

b. The internal control goes beyond the financial and accounting issues and the protection of the assets of the establishment, as it is a comprehensive system for the mechanisms of the control provisions set by the administration.

c. The internal control is designed to provide reasonable, logical, and not absolute assurances related to the achievement of all the objectives of the enterprise, which include protecting the enterprise's resources from misuse, relying on reports and 
financial statements, and achieving efficiency and effectiveness for all enterprise activities.

d. Internal control is not a goal in itself, but a means to achieve a set of goals and is an integral part of administrative functions.

e. Effective internal control depends on the availability of appropriate accounting systems, and the accounting system depends on providing documents and records appropriate for those accounting systems to reveal the locations of administrative and financial corruption.

f. Despite the presence of internal control, the phenomenon of administrative corruption in government agencies in many developing countries is almost general and tangible, and it is present in developed countries, but to a lesser degree than in developing countries.

g. Corruption is an old phenomenon, and it was the main factor in the collapse and fall of most civilizations and regimes, and the engine of wealth and uprisings, old and new.

Considering the presented conclusions, we suggest the following recommendations:

a. Paying attention to social upbringing and instilling the prevailing cultural values that establish ethics and positive behaviour in society, and the dissemination of advanced civilizational awareness that rejects corruption of all kinds

b. The necessity of giving the internal control the attention of the various administrative bodies and establishing special units for internal control in the organization and linking them with the higher management to give it a sufficient degree of independence

c. The necessity of paying attention to the supervisory methods, which are essential tools for the supervisory work, and one or more methods can be used in one unit of the units.

d. Encouraging cooperation between the Supreme Audit Institutions in the field of computer insertion in the supervisory work and encouraging the Supreme Audit Institutions to develop work manuals and guidelines for use in examining the effectiveness of internal control.

e. The necessity of adhering to the general standards issued by the Internal Control Standards Committee, with interest in developing those standards that must be adhered to under automated systems.

\section{References}

[1] Abou. Z, Ramy, (2016), Master s Degree Project Internal Control Application, Empirical Evidence from Swedn.

[2] Al - Frijawy, Jawad \& Militaru, Constantin , \& Ali ,methaq Hashim , 2018, The Phenomenon of the Spread of Administrative and Financial Corruption in IRAQ Despite the Multiplicity of Oversight Bodies, American Scientific Research Journal for Engineering Technology, and Sciences, Issn (Print ) 2313 - 4410 , Issn ( Online ) 2313-4404 .

[3] AL - Hosseini , Murtadha Mohammed , \& AL - Tamimi , Layth Ali , \& Kadhim , Ezzaddin Hasan , 2019, Reducing Financial and Administrative Corruption Through the Ingredients of the Internal Control System, Research Journal of Finance and Accounting, VOL. 10, No . 16 .

[4] Andersson, Jessica , \& Vilo, Tuulikki , 2016, How do Internal Auditors Become Comfortable in their Role within Risk Management , Master s Thesis , Department of Business Studies , Uppsala University . 
[5] Basem , Artimi , \& saeh ,Mohamed , 2019, the Impact of Corruption on some Aspects of the Economy, article in International Journal of Economics and Finance, Doi: 10.5539 / ijef.v5n8p1.

[6] Bubilek, Olga , 2017, International Business Degree Thesis Bachelor of Business Administration , Degree Program : International Business, Identification number 15474

[7] Claros , Augusto Lopez , 2013 , Removing Impediments to Sustainable Economic Development the Case of Corruption, Policy Research Working Paper .

[8] Grigore, Ana-Maria, \& Dragan, Irin Mehrdad , 2016 , against Administrative Corruption within governmental Organizations from motto to Practice, Journal " Problems and Perspectives in management " Founder LLC " Consulting Publishing Company " Business Perspectives .

[9] Moeller , Robert R. 2009 , Brink s Modern Internal Auditing A Common Body of knowledge , Published by John Wiley \& Sons, Inc. , Hoboken, New Jersey, $7^{\text {th }}$ Edition .

[10] Moeller , Robert R. 2014 , Executive s Guide to Cosa Internal Control Understanding and Implementing the New Framework, Published by John Wiley \& Sons , Inc. , Hoboken, New Jersey

[11] Mousavi , Parvenu , \& Pourkiani, Masood, Administrative Corruption : Ways of tacklin the Problem, Natural and Social Sciences Vol. 2 , No. 3 (s ), PP. 1178 - 187Issn 1805 - 3602.

[12] Paraskevi , Theodoridou , 2016, The Effectiveness of Internal Audit and Internal Control Systems in Greek Banks, School of Economics, Business Administration \& Legal Studies A thesis Submitted for the Degree of Master of Science ( NSC ) in International Accounting .

[13] Peteres , Michel , 2016, Accounting Auditing and Control , thesis does an Association Exist between the Personal determinants of the CEO and CFO and Corporate internal Control Quality, Erasmus University Rotterdam .

[14] http://libguides.csu.edu.au>c.php. 